\title{
Los enfoques teóricos y metodológicos de la militancia*
}

\author{
Bernard Pudal**
}

\begin{abstract}
Resumen
Los estudios en ciencias sociales sobre la militancia han evolucionado profundamente en Francia en la última mitad del siglo pasado. Este breve trabajo, dedicado a la evolución de las modalidades de análisis de la militancia, pretende proponer un bosquejo, centrado por cierto en el caso francés pero abierto al aporte de las teorías anglosajonas. Esta historia particular asocia en el marco de configuraciones relativamente estabilizadas durante un período más o menos largo de tiempo, objetos (tipos de militancia), investigadores (tipos de investigadores), paradigmas analíticos (maneras de elaborar una problemática a partir de sus preguntas) y métodos (técnicas de encuesta). Cronológicamente, se pueden distinguir cuatro "configuraciones" que se diferencian unas de otras por razones didácticas. La primera, que puede llamarse la configuración "heroica", se centra en el activista obrero, particularmente en el militante comunista. La segunda configuración que comienza alrededor de 1975 es denominada como el período del militante "retribuido". La tercera configuración, inaugurada en Francia por el gran movimiento de huelgas de otoño de 1995, corresponde a lo que se podría llamar la de los "nuevos militantes", o si se prefiere la del militante "distanciado". Finalmente, la cuarta configuración se caracterizaría por una ampliación de las militancias estudiadas y apuntaría más bien a fijar los términos de una comparación controlada que a confrontar la figura del activista obrero con la del militante distanciado. Esta cuarta configuración asume también nuevos desafíos: el desinvolucramiento, el letargo militante, la consideración de los resortes a la vez psicológicos y sociales del compromiso, etc. Curiosamente, se verá que más allá de las diferencias, estas configuraciones resultan ser comparables.
\end{abstract}

Palabras clave: Compromiso - militancia - movimientos sociales - historia de las ciencias sociales - metodología.

\begin{abstract}
Social science studies about militancy in France have strongly evolved during the final half of the last century. This brief work, dedicated to the evolution of the modalities of analysis of militancy, aims at presenting an outline focused on the French case but open to Anglo-Saxon theories. It associates objects (types of militancy), researchers (types of researchers), paradigms (how to elaborate a problem) and methods (survey techniques) studied within relatively stabilized configurations during a relatively long period of time. Chronologically, four "configurations" can be distinguished for didactical purposes, although they are naturally intertwined. The first one, the "heroic" configuration, is focused on the worker activist, specially the communist militant. The second begins around 1975 and can be named as the "rewarded" militant configuration. The third configuration starts in France with the big strike movement of 1995 and could be called the "new militants" or, if preferred, the "distantiated militants" configuration. Finally, the fourth configuration characterizes itself by expanding the previous forms of militancy. It invites to fix the terms of a controlled comparison between the worker activist and the distantiated militant instead of opposing them. This last configuration also assumes new challenges: disengagement, militant lethargy, the consideration of both psychological and social mechanisms of disengagement, etc. Curiously, beyond its differences, these configurations remain comparable.
\end{abstract}

Keywords: Engagement - militancy - social movements - history of social sciences - methodology.

* Este artículo se enmarca en el Proyecto de Investigación ECOS-CONICYT C05H01.

** Profesor de Ciencia Política de la Universidad de París X-Nanterre e Investigador del Centro Nacional de la Investigación Científica (CNRS), París, Francia. Correo electrónico: bernard.pudal@csu.cnrs.fr 


\section{INTRODUCCIÓN 1}

Los estudios en ciencias sociales sobre la militancia han evolucionado profundamente en Francia en la última mitad del siglo pasado. Principalmente enfocados en el movimiento obrero de los años cincuenta y sesenta, los estudios de este tipo se refieren hoy en día a todas las formas que adquieren los compromisos militantes, ya sea de derecha o de izquierda, humanitarios o religiosos. Este breve trabajo, dedicado a la evolución de las modalidades de análisis de la militancia, sólo pretende proponer un bosquejo, inserto en una sociología de los conocimientos y de los científicos, centrada por cierto en el caso francés, pero abierta al aporte de las teorías anglosajonas, sobre todo en el último período. Los campos científicos nacionales se caracterizan por sus lógicas propias y por la manera en que se reapropian los aportes externos. Por supuesto, no se puede tratar más que de un bosquejo, en la medida en que contar la historia de la militancia supondría una investigación detallada acerca de las trayectorias biográficas de los investigadores, de los campos disciplinarios en los que se inscriben, de sus rivalidades, de los intercambios internacionales y sus funciones en las competencias internas. Creo sin embargo que no se puede proceder de otra manera, debido a la imbricación en las ciencias sociales de los desafíos científicos y sociales, en especial cuando éstas se dedican a estudiar los diferentes tipos de militantes y de militancia; en otras palabras, la política y el cuestionamiento del orden social. Frecuentemente, los investigadores que se interesan por tales objetos están implicados en el objeto. Por otra parte, la mayoría de las opciones que éstos toman -elección del tema, del modo de análisis, de la disciplina, etc.- no se originan en un mundo etéreo y puramente "racional", sino en el mundo real en el que el investigador se encuentra inmerso. El investigador siempre se inscribe -y al principio sin saber ni por qué ni cómo- en un estado del arte de las investigaciones y de las disciplinas con el cual se relaciona más bien mediante su sistema de afinidades (sociales, de disciplina, de escuelas y políticas). En consecuencia, es por estas razones epistemológicas -que no corresponde exponer aquí- que prefiero bosquejar una historia social de los modos de análisis de la militancia en sus relaciones con tipos de militancia, con momentos y conflictos específicos. La historia sociológica, como siempre, es un excelente antídoto para escrutar el inconsciente ideológico que estructura nuestras investigaciones y tratar de dominar mejor sus efectos.

\section{Las cuatro configuraciones}

Esta historia particular -que, si se quiere, atañe a la historia de las ciencias socialesasocia en el marco de configuraciones relativamente estabilizadas durante un período más o menos largo, objetos (tipos de militancia), investigadores (tipos de investigadores), paradigmas analíticos (maneras de elaborar una problemática a partir de sus preguntas) y métodos (técnicas de encuesta).

1 Los trabajos citados directa o indirectamente en este artículo son demasiado numerosos como para mencionarlos todos. Acerca de la primera y de la segunda configuración, se puede consultar la bibliografía del trabajo de Gérard Noiriel (1986); acerca de la tercera configuración, véanse Lilian Mathieu (2004) y Erik Neveu (1996). 
Cronológicamente, se pueden distinguir cuatro "configuraciones", que diferenciaremos unas de otras por razones didácticas, aunque se encuentren naturalmente entrelazadas en la realidad.

La primera, que puede Ilamarse la configuración "heroica", se centra en el activista obrero, particularmente en el militante comunista. Cubre el período que va desde 1945 hasta mediados de los años setenta aproximadamente. Para los historiadores, corresponde por un lado a la época de los estudios sobre la clase obrera, analizada de distintas maneras y, por otro, a las biografías de militantes; es en particular en esa época que se da inicio a una gran aventura, a la vez científica y memorial, la del Dictionnaire Biographique du Mouvement Ouvrier Français (DBMOF) dirigido por Jean Maitron. También corresponde a una época dentro de una historia universitaria, a la vez muy productiva desde el punto de vista científico y movida por el anticomunismo, representada principalmente por una de las grandes historiadoras francesas del comunismo, Annie Kriegel.

La segunda configuración empieza alrededor de 1975. Surge en torno al cuestionamiento, que recurre a diferentes paradigmas teóricos, de un supuesto inherente a la mayor parte de las investigaciones del período anterior, el presumido "desinterés del militante". Se puede referir a esta configuración como la del período del militante "retribuido". En Francia, una palabra simboliza ese tipo de desilusión materialista luego del lirismo militante utópico propio de mayo de 1968: la palabra "retribución", idónea para disipar el idealismo implícito de los estudios anteriores, a pesar del riesgo, como lo veremos, de caer en un utilitarismo poco convincente. Ya quedó claro que la manera francesa de expresar esta desilusión militante tiene que ver con la teoría de Mancur Olson (1966) sobre las "incitaciones selectivas". Aunque el cuestionamiento del "desinterés" militante sea más común en ciencia política y en sociología, también tendrá sus efectos en historia, al conducir a un abandono progresivo del "mito" de "la" clase obrera, en beneficio de estudios dedicados, por ejemplo, a los encuadramientos dirigentes ${ }^{2}$. Esta segunda configuración va de la mano con la crisis cada vez más aguda del movimiento obrero francés y con la decadencia del Partido Comunista Francés (PCF). Corresponde igualmente a una fase de repliegue o de desafiliación, que alimenta la idea de una crisis de la militancia, la cual dará lugar en Francia a un libro sucinto, titulado La fin des militants? (Ion, 1997). Este trabajo asegura la transición entre esta segunda configuración y la siguiente, como lo señala el punto de interrogación. El imaginario militante implícito en las investigaciones de estas dos primeras configuraciones está construido en torno al activista obrero y, en Francia, dada la importancia del PCF en el movimiento obrero francés, en torno al militante comunista.

La tercera configuración, que corresponde a lo que se podría llamar los "nuevos militantes", o si se prefiere el militante "distanciado", inaugurada en Francia por el gran movimiento de huelgas de otoño de $1995^{3}$, se caracteriza a la vez por la reaparición de

Véanse entre otros a Offerlé (1984) y Bernard Pudal (1989).

N.d.T.: Estas huelgas son las más importantes desde las de mayo de 1968. Desde el 24 de noviembre hasta el 15 de diciembre sacuden tanto al sector público como privado, en un movimiento de rechazo al plan de reforma al sistema de jubilación y seguridad social propuesto por el primer ministro Alain Juppé. 
las movilizaciones colectivas y de protesta, con los Nuevos Movimientos Sociales (NMS), por una nueva generación de investigadores, pero también por el uso muy significativo de herramientas analíticas creadas por autores anglosajones: de Erving Goffman a Charles Tilly, de Anthony Oberschall a Doug McAdam, de David Snow a James Scott. Esta tercera configuración se centra en la comparación histórica entre militancias: ¿se puede oponer a un militante disciplinado, entregado, antiguo, cuyo prototipo sería el militante "estalinista", un nuevo tipo de militante, a menudo calificado de "distanciado"? Esta pregunta suscita a su vez otras: ¿cómo dar cuenta del trabajo cognitivo (intelectual) de los militantes? ¿Cómo dar cuenta sin reduccionismo de las lógicas complejas que dan origen a las carreras militantes? ¿Se puede hablar de una militancia "individualista"?

Después de caracterizar brevemente estas tres configuraciones y a modo de conclusión, intentaré mostrar que probablemente ya hemos entrado en una cuarta configuración, la cual recogería los avances de las tres primeras. Se caracterizaría por una ampliación de las militancias estudiadas y apuntaría más bien a fijar los términos de una comparación controlada que a oponer al activista obrero con el militante distanciado. Esta cuarta configuración asume también nuevos desafíos: el desinvolucramiento, el letargo militante, la toma en cuenta de los resortes a la vez psicológicos y sociales del compromiso, etc. Curiosamente, veremos que más allá de las diferencias, estas configuraciones son comparables. Pero no se pueden comparar seriamente sin otorgar el lugar que se merece a la crisis bisagra de mayo-junio del 68 , la cual ha dado lugar hasta la fecha a muy pocos estudios científicos, a pesar de que en ella se juegan ciertas filiaciones, herencias y reinterpretaciones posteriores.

\section{LA PRIMERA CONFIGURACIÓN: EL ACTIVISTA OBRERO, PARADIGMA DEL MILITANTE HEROICO (1945-1975)}

El paradigma científico dominante en historia social asociaba, durante los años cincuenta y sesenta, una visión macrohistórica (basada en parte en el paradigma labroussiano) (Revel, 1996) y agregados reificados (las "clases" sociales como actores de la historia). El movimiento obrero fue entonces tomado como objeto en importantes tesis de historia. Desde la historia de la huelga (Michèle Perrot) hasta los mineros de Carmaux (Rolande Trempé); desde la historia del movimiento socialista y obrero en la ciudad de Toulon (Maurice Agulhon) hasta los guesdistas ${ }^{4}$ (Claude Willard), esta historia social ha permitido integrar una historia militante, en la que el grupo social cumple una función de héroe colectivo, siendo los grupos militantes su expresión más consciente. Estas tesis, que sentaron las bases de una historia social de los grupos obreros, fueron marcadas, implícita y explícitamente, por la empatía de intelectuales comprometidos con el movimiento obrero. De ahí la importancia otorgada muy temprano al activista obrero, lo que confirió a las biografías de militantes un lugar de entrada determinante,

4 N.d.T.: Partidarios de Jules Guesde (1845-1922), político socialista francés. Guesde encarna el arquetipo del militante pobre, incorruptible, que viaja por Francia para dar a conocer el socialismo revolucionario. 
aun cuando el paradigma labroussiano y la Escuela de los Annales ${ }^{5}$ más bien desconfiaban del género biográfico.

Al margen de la historia universitaria, en los años de posguerra, abundan las biografías de militantes. La obra de Maurice Dommanget, entre las dos guerras, es tal vez la más representativa desde este punto de vista. Dommanget era profesor de primaria, militante sindicalista, y se convirtió en una especie de erudito y de historiador aficionado (pero muy serio) del movimiento obrero ${ }^{6}$.

En el corazón mismo de la comunidad de historiadores, el Dictionnaire Biographique du Mouvement Ouvrier Français (editorial de l'Atelier) pasa a ser la obra colectiva más destacada de una comunidad de historiadores políticamente dividida, pero unificada por su relación de empatía con el "movimiento obrero". Iniciada a principios de los años sesenta, esta gran obra colectiva, compuesta por 44 volúmenes para el período 1789-1940, reúne 110.000 reseñas biográficas. El elogio brindado a los militantes era tal que incluso aquellos de quienes sólo se disponía de información incompleta podían ingresar al diccionario. ¿Acaso todos los militantes no merecían el reconocimiento de la ciencia histórica y de la memoria colectiva? Algunas reseñas contaban sólo con unas líneas. Eso explica por qué el DBMOF puede ser analizado como "un lugar de memoria" (Perrot, 1996), una especie de Panteón de papel de los grandes hombres del activismo obrero, pero también de los pequeños. Aquello explica también las "rehabilitaciones", en contra de una visión "dominante" marcada por el éxito del comunismo (relativo pero indiscutible en Francia desde 1936 hasta fines de los años sesenta), de personajes alternativos olvidados, subestimados o descalificados (los anarquistas de Jean Maitron ${ }^{7}$, los sindicalistas revolucionarios de Jacques Julliard ${ }^{8}$, el grupo Monatte de Colette Chambelland [1999], etc.). Las páginas heroicas de la historia del movimiento obrero o de los obreros en movimiento serán representadas por diversos dirigentes emblemáticos (Babeuf, Blanqui, Proudhon, Lenin o Trotsky y naturalmente Jaurès según Madeleine Rebérioux ${ }^{9}$, entre otros) cuya variedad da cuenta de las diferencias políticas existentes entre los mismos historiadores.

En ese contexto, la historia del PCF y de los militantes comunistas se transformó en un desafío central. Existía por un lado una historia edificante, realizada por los historiadores casi oficiales del PC y, por el otro, una historia política de los acontecimientos del comunismo, que cuestionó en los años sesenta esta historia instrumentalizada ${ }^{10}$. El lugar central que ocupaba la militancia comunista hizo que las controversias de la época se focalizaran en Annie

$5 \quad$ N.d.T.: La Escuela de los Annales es una escuela historiográfica, denominada así por la publicación de la revista francesa Annales d'Histoire Économique et Sociale (fundada en 1929), en la cual fueron publicados por primera vez sus planteamientos.

Sobre Maurice Dommanget, véanse Actes du colloque international de Beauvais (1994).

N.d.T.: Historiador francés (1910-1987) especialista del movimiento obrero.

N.d.T.: Periodista e intelectual francés (1933-), historiador de formación y ex responsable sindical.

N.d.T.: Historiadora francesa (1920-2005) especialista de la III República y de Jean Jaurès.

10 Sobre esta historiografía, véase Dreyfus et al. (2004), en particular las contribuciones sobre la historiografía del comunismo en la primera parte. 
Kriegel quien, en su tesis de historia (1964), trató de deconstruir el relato edificante acerca de los orígenes del comunismo. Luego publicó en 1968 un ensayo sobre Les Communistes français que marcó su época, en el cual desarrollaba la temática de la "contra-sociedad" comunista y hacía del "permanente" comunista un militante abnegado, disciplinado, pero al mismo tiempo común y ciego.

\section{LA SEGUNDA CONFIGURACIÓN: EL CUESTIONAMIENTO DE LOS "MITOS" O EL “MILITANTE RETRIBUIDO" (1975-1990)}

Norbert Elias definió al sociólogo como un cazador de mitos. Es el caso de esta segunda época. Simplificando mucho, podemos decir que durante ella se desplazó la problemática central de manera cognitiva, científica y política a la vez, lo que afectó progresivamente el paradigma hasta entonces dominante. Ese desplazamiento de problemática ha seguido múltiples derroteros, variables según los países y dentro de cada país, pero que parecen hoy en día seguir el mismo rumbo. Dicho período ha sido caracterizado claramente por Christophe Charle (1996) en su estudio: Trois âges de la biographie collective. Se trata de una tendencia que cuestiona progresivamente el substancialismo y la reificación de los colectivos propios de estos trabajos de historiadores: "siguiendo a Bachelard y transfiriendo su modelo de psicoanálisis del conocimiento científico desde la química hasta la historia social, se puede asimilar el paso desde la macro hacia la microhistoria social al rechazo progresivo del defecto frecuente de la historia social tradicional, el substancialismo: las clases eran asimiladas a cosas dotadas de cualidades intrínsecas o a actores colectivos dotados de una conciencia y de una voluntad unificada, como los próceres de antaño" (Charle, 1996: 58). El substancialismo no se reduce al grupo social (la clase), sino que afecta también otras categorías de análisis, que deben ser deconstruidas, porque quedan vinculadas con la reificación de los actores colectivos: "el" militante, "el adherente", "la adhesión", "el" partido o "la organización", "la" dirección de tal agrupación, etc.

Limitándonos a la clase obrera, numerosos trabajos han contribuido a rehabilitar la construcción del grupo obrero mediante una historia menos substancialista, en una perspectiva sociogenética. Nos referimos evidentemente al trabajo pionero de Edward Palmer Thompson, The making of the working class (1963), cuyo alcance metodológico sólo fue comprendido en Francia cuando fueron reunidas las condiciones intelectuales para su recepción (1988). Sin entrar en el detalle de estas investigaciones acerca de las cuales Gérard Noiriel ha propuesto un esbozo de síntesis, con un título que rompe deliberadamente con el substancialismo, Les ouvriers dans la société française, $X I X^{\circ}-X X^{\circ}$, esta nueva perspectiva modificó profundamente los marcos interpretativos de los análisis anteriores. Este cambio es innegable y se explica, según Antoine Prost (1995: 203 y ss.), "por el aporte de otras ciencias sociales, cuyas problemáticas y métodos han inspirado a los historiadores" (ciencia política, lingüística, sociología, etnología, etc.) y porque "estuvo relacionado con los problemas que agitaron la sociedad francesa" (el feminismo, "el efecto 1968" en materia de análisis de las instituciones de control social y la cuestión de la inmigración). 
Este desplazamiento de la problemática no ha desembocado en un nuevo paradigma histórico unificado, sino más bien en la multiplicación de los puntos de vista o de las escalas de análisis. Sin embargo, es posible resaltar algunos puntos clave. En primer lugar, el recurso cada vez más frecuente a la prosopografía (o biografía colectiva) permite estudiar grupos militantes más restringidos y de acuerdo a diversas perspectivas. Los análisis del DBMOF, a través de los proyectos prosopográficos que el diccionario permite, se inscriben dentro de esta evolución, como lo prueban varias investigaciones acabadas o todavía en curso acerca de los brigadistas franceses que combatieron en la España republicana, los sacerdotes obreros o los activistas de la JOC (Juventud Obrera Cristiana ${ }^{11}$ ), las mujeres militantes, por ejemplo. Sin embargo, esta toma de posición "realista" generó tensiones. Los trabajos de Jacques Rougerie sobre la Comuna de París, o más precisamente acerca de los communards (partidarios de la Comuna), levantaron una polémica debido a que parecían empañar la imagen ideal del communard. En efecto, Jacques Rougerie puso al descubierto un pueblo más heterogéneo y menos revolucionario que aquel con el cual se había "soñado" hasta el momento.

Por otra parte, biografías más contrastadas y autobiografías autocríticas de militantes remplazaron las biografías o autobiografías otrora edificantes. Finalmente, el análisis de las lógicas de agregación de los grupos militantes estuvo acompañado por una nueva mirada sobre los obreros, considerados a partir de ese momento en sí mismos, independientemente de su participación posible o deseada en el "movimiento obrero". Los trabajos alemanes de Alf Lüdtke, por ejemplo, al poner el acento en la "distancia" obrera o la microhistoria italiana (véanse los trabajos de Maurizio Gribaudi) son buenos ejemplos de aquello. Los obreros, lejos de sentirse representados por el movimiento que pretendía hablar en su nombre, se sentían a menudo indiferentes, incluso se mostraban conservadores, sin mencionar a quienes se prestaban para propósitos más extremos (fascismo, Frente Nacional' ${ }^{12}$ ).

\section{Del desinterés hasta el estudio de las retribuciones de la militancia y de las lógicas de las movilizaciones}

La segunda dirección que toma este desplazamiento de la problemática, que disociamos del resto por razones analíticas pero también porque ha sido producto de la sociología y de la ciencia política, se inscribe más específicamente en la historia de la evolución de los análisis sociológicos de la movilización y de la representación.

Movilizando herramientas conceptuales diversas, y a veces incompatibles, la ideología del altruismo está en la esencia de la figura del "activista obrero", pero más habitualmente de la militancia en general, elemento que ha sido progresivamente cuestionado. El "aura" del "militante" proviene de su encarnación del grado más alto de compromiso y de altruismo,

11 N.d.T.: Rama juvenil de la Acción Católica destinada a promover la Doctrina Social de la Iglesia en los movimientos juveniles. Es fundada en 1924 por el sacerdote belga Joseph Cardijn, que pasará a ser cardenal.

12 N.d.T.: Partido político francés fundado en 1972 y habitualmente enmarcado en la extrema derecha. 
pudiendo llegar hasta el sacrificio de su vida, siempre a costa de una represión multiforme que lo acecha (despido, encarcelamiento, violencias físicas, ausencia de promoción). Ya sea por medio del paradigma olsoniano (Olson, 1966) (remitimos a la síntesis que propone de éste Eric Neveu en su Sociologie des mouvements sociaux, 1996), o por medio de una sociología de las retribuciones de la militancia (Gaxie, 1977, 2005), cuyo origen científico se remonta a la obra de Max Weber, o por medio de una reflexión sociológica acerca de los fenómenos de delegación política (Bourdieu, 1984), esta duda construida científicamente y combinada con la resistencia al substancialismo ha dado lugar a la elaboración de múltiples marcos de análisis de los movimientos sociales. Al introducir una ruptura entre la militancia y los motivos aducidos por los militantes, entre los militantes y los grupos que representan, este desplazamiento de la problemática obliga a interrogarse sobre las contradicciones inherentes a la militancia. En conclusión de su discusión crítica al paradigma olsoniano, François Chazel (1986) subraya que, si bien el tipo de análisis fundado en el paradigma económico no arroja más que una luz parcial sobre los fenómenos conjuntos de la movilización y de la acción colectiva, ha tenido por lo menos -y sigue en parte teniendo- virtudes críticas, por su carácter incisivo que pone al desnudo falsas evidencias sociológicas; la paradoja de la acción colectiva seguramente ha ayudado a los sociólogos a medir mejor la importancia de los obstáculos a una movilización demasiado considerada como algo obvio.

El conjunto de las relaciones entre los representantes del grupo obrero -cualesquiera sean éstos y cualesquiera sean sus representantes- y el mismo grupo se vuelve "problemático" en todos los sentidos de la palabra ${ }^{13}$.

No es de ninguna manera casual que estas tomas de posición realistas se traduzcan en obras -a veces ensayísticas- que, durante los años setenta, se preguntan e interrogan los involucramientos militantes. Desde el pequeño libro de Daniel Gaxie sobre Les Professionnels de la politique (1973) hasta su artículo sobre las retribuciones de la militancia (1977), desde el trabajo de Daniel Mothé (1973), significativamente titulado recurriendo a un oxímoron, Le métier du militant, hasta Qu'est-ce qui fait courir les militants? Analyse sociologique des motivations et des comportements deYvon Bourdet (1976); sin olvidar la reedición de Les partis politiques de Roberto Michels $(1911,1971)$ o el trabajo de Serge Quadruppani (1979) Des permanents des partis politiques, para dar sólo algunos ejemplos, Ilegamos progresivamente a un conjunto de análisis que desacralizan el activismo obrero, interrogan sus "motivaciones", dan una interpretación a veces psicológica de su entrega, insisten siempre en lo que está en juego específicamente en la representación, en las predisposiciones sociales a jugar el papel de portavoz, en las incitaciones selectivas o en las retribuciones de la militancia (retribuciones simbólicas, terapéuticas, financieras, aspiracionales, culturales, en términos de capital social, etc. $)^{14}$.

13 Sobre esta problematización véase el artículo fundamental de Pierre Bourdieu (1984).

14 Véase el artículo fundador de Daniel Gaxie (1977) y su respuesta a sus críticos (Gaxie, 2005). 
Ese desplazamiento de la problemática, más bien de carácter histórico en el primer caso, y sociológico en el segundo, desembocó progresivamente en una multitud de investigaciones históricas y sociológicas acerca de los determinantes sociales del compromiso militante y de los intercambios que presiden al encuentro entre individuos más o menos predispuestos a comprometerse y organizaciones (partidos, sindicatos) ${ }^{15}$. Los análisis sociológicos de las trayectorias militantes (encuestas sociológicas, prosopografías y estudios de las elites militantes) ${ }^{16}$, los estudios sociográficos de grupos militantes (principalmente las elites dirigentes) ${ }^{17}$ han interrogado en especial los mecanismos y las condiciones de posibilidad de la legitimación de un personal político obrero socialmente ilegítimo.

Dicho desplazamiento de la problemática no pudo evitar ciertas derivas: la analogía económica que transforma al militante en un ser interesado y calculador y hace de la organización a la que pertenece una "empresa", puede llevar a un conjunto de interpretaciones reductoras, más o menos conscientes, en las que los intelectuales comprometidos con el movimiento obrero aparecen necesariamente como unos "fracasados" o "desclasados" (Jeanine Verdès-Leroux), y en las que los activistas obreros sólo se mueven por los intereses ligados a las incitaciones selectivas y por las diversas ventajas que dan los puestos a los cuales tienen acceso, sean o no retribuidos. A partir de ese momento, mediante una suerte de espiral denunciador, los héroes de ayer pierden su atractivo y muchos militantes, en particular los militantes y cuadros comunistas, y de manera más general todos aquellos que se pretendían "revolucionarios", pasan a ser hombres comunes y corrientes (Kriegel, 1968), cínicos y peligrosos, en todos los casos animados por el deseo ilusorio de regenerar al hombre (Furet, 1995). Louis Auguste Blanqui ${ }^{18}$, por ejemplo, sufre esa suerte. Algunos episodios, ayer gloriosos, como la historia de las brigadas internacionales, sólo aparecen hoy bajo el ángulo de los conflictos internos del bando republicano o de lo que estaba en disputa en los movimientos diplomáticos "totalitarios" de la época. Se podría decir que los hombres de la sombra salen a la luz. Y la aversión hacia el objeto se hace explícita.

Esta segunda configuración, aun focalizada en el militante del movimiento obrero, sucede en un momento en que se produce en Francia un descenso de las luchas colectivas así como una crisis de confianza en esa militancia. El estancamiento, y luego la decadencia del Partido Comunista, acompañada por las revelaciones indiscutibles del terror estalinista, son propicias para las instrumentalizaciones políticas que apuntaban a desacreditar a los militantes.

15 Véase por ejemplo Luc Berlivet y Frédéric Sawicki (1994).

16 Uno de los primeros estudios sobre los militantes fue efectuado por Lagroye et al. (1976).

17 Mi libro, Pudal (1989), intentaba precisamente, mediante el recurso de la biografía colectiva de la elite de los cuadros y dirigentes comunistas, estudiar el encuentro entre trayectorias obreras consideradas socialmente ilegítimas y el Partido Comunista en fase de "estalinización".

18 N.d.T.: Activista político revolucionario (1805-1881). 


\section{LA TERCERA CONFIGURACIÓN: NUEVAS MILITANCIAS, NUEVOS MOVIMIENTOS SOCIALES, NUEVOS INVESTIGADORES (1990-2005)}

Las dos primeras configuraciones están centradas en el movimiento obrero y son el fruto de investigadores y académicos comprometidos de manera más o menos continua con el movimiento obrero. La tercera configuración es muy distinta. Se singulariza por una triple "novedad": la novedad de las militancias estudiadas, de los investigadores que las estudian y de las teorías utilizadas.

De ahora en adelante, el conjunto de las nuevas luchas pasa a ser objeto de estudios, de tesis y de informes de investigación ${ }^{19}$ : los NMS (ATTAC, SOS Racismo ${ }^{20}$ ); el altermundialismo; las luchas humanitarias; las luchas de los "sin" ("sin documentos", "sin domicilio", "sin trabajo"); asociaciones antiguas poco estudiadas, pero que aparecen ahora como precursoras (la Liga de Derechos Humanos ${ }^{21}$ ); nuevas organizaciones sindicales (la Confederación Campesina de José Bové22; los sindicatos SUD-Solidarios Unitarios Democráticos ${ }^{23}$ ); las luchas en torno a problemas específicos (el SIDA, las cuestiones homosexuales, la prostitución, la homofobia). Finalmente, mayo del 68 es estudiado en trabajos universitarios. Una de las primeras tesis de ciencia política dedicadas a dicho período efectuó un análisis comparativo entre Francia e Italia con el objeto de indagar las razones que llevaron a Italia y no a Francia a pasar a la violencia revolucionaria (Sommier, 1998).

Se establecieron redes de investigadores, particularmente numerosas en ciencia política; al mismo tiempo aparecieron nuevas referencias teóricas, caracterizadas principalmente por recurrir a las teorías americanas de los movimientos sociales: sociología de la movilización de los recursos, repertorio de la acción colectiva, estructura de oportunidades políticas, sociología de las carreras militantes, procesos de framing. De aquello resultaron numerosos estudios y debates acerca, por ejemplo, de la teoría de las estructuras de oportunidad política. Como resultado de la discusión, esta teoría perdió su carácter "estructural", pero conservó su relevancia al tomar en cuenta los factores contextuales que favorecen u obstaculizan las acciones militantes. Numerosos estudios hicieron entonces referencia a los autores y a los modos de análisis norteamericanos:

- ya sea en el análisis de largo plazo de las formas de protesta (Tilly, 1984), basadas en las transformaciones de los repertorios de acción en relación con el modo de construcción del Estado moderno;

19 Agrikoliansky (2002); Siméant (1998); Collovald (2002); Fillieule (1997); Fillieule y Mayer (2001); Juhem (2001); Mathieu (2001); Sommier (1998). Para una visión de conjunto sobre los NMS, véanse Crettiez y Sommier (2002) y Sommier (2003).

20 N.d.T.: SOS Racisme es una asociación francesa creada en 1984 para luchar contra todas las formas de discriminación racial.

21 N.d.T.: La Ligue des Droits de l'Homme es una asociación francesa fundada en 1898 para defender al capitán Alfred Dreyfus, judío acusado equivocadamente de traición.

22 Véase en este número el artículo de Ivan Bruneau (2008).

23 N.d.T.: Sindicatos y federaciones miembros de la Unión Sindical Solidarios, inicialmente fundada en 1981, que no forman parte de las cinco confederaciones de sindicatos de asalariados franceses consideradas representativas del Estado. 
- sea desde el punto de vista de diferentes tipos de acción y de sus lógicas: huelgas, manifestaciones, etc.;

- sea también como una reflexión acerca de los ciclos de la movilización colectiva (ciclo de vida pública/felicidad privada) o de las alternativas de la acción (exit-defección, voiceintervención oral crítica, loyalty-disciplina/lealtad) (Hirschman, 1970);

- o de manera más general, acerca de las condiciones de las movilizaciones colectivas (Oberschall, 1973).

Esta rama de la disciplina, con sus autores predilectos, sus nuevos objetos, sus nuevos investigadores, se diferencia netamente del período anterior. Los recién llegados, es decir, los jóvenes investigadores, al importar trabajos anglosajones "mataban dos pájaros de un tiro": se dotaban de una suerte de identidad científica propia y se desmarcaban a la vez de la generación anterior de cientistas políticos o de historiadores, cuyo universo intelectual estaba ligado a las teorías dominantes en los años sesenta y setenta: el marxismo, la historia social, la sociología de la dominación, principalmente representada en Francia por la sociología de Pierre Bourdieu y de sus émulos; una sociología que prolongaba y superaba a Marx, Durkheim y Weber.

Esta división tuvo naturalmente dimensiones político-científicas. Desde los años ochenta, el campo intelectual francés ha sido en efecto el objeto de una dura batalla, con una tendencia marcada al desplazamiento hacia la derecha que, en el terreno sociológico, se manifestó en y por los usos del "individualismo metodológico" como paradigma de ruptura frente al "sociologismo". Esta disputa se expresó en Francia mediante discusiones y críticas suscitadas por un libro titulado de manera significativa La fin des militants? de Jacques lon (1997), trabajo que cierra esta segunda configuración constatando el fracaso de la militancia comunista.

\section{Una controversia y sus efectos}

Jacques lon reivindica una suerte de método "empírico" que debe develar progresivamente sus implicancias teóricas. Estudia tanto las asociaciones regidas por la Ley de $1901^{24}$ como los partidos políticos o los sindicatos. Al constatar que estas organizaciones se vuelven más numerosas simultáneamente (vale decir, durante la segunda mitad del siglo XIX), sugiere una posible "interrelación". Por otra parte, la temática de la crisis del activismo se aplica tanto a los sindicatos como a los partidos políticos, al igual que a las nuevas militancias, puesto que estas últimas se caracterizarían por una suerte de "militancia distanciada". Al rechazar tanto el método que convierte el discurso de los agentes en la verdad de sus prácticas, y que hace del analista que busca en las razones biográficas o sociográficas las causas del compromiso alguien capaz de decir la verdad acerca de prácticas desconocidas por los mismos agentes, Ion (1997) pretende interesarse por las "formas" del compromiso, en un momento en que "el

24 N.d.T.: Una Asociación Ley 1901 es una asociación sin fines de lucro regulada por la Ley del 1 de julio de 1901, la cual definió un marco jurídico para la creación de las asociaciones que no existía en Francia, aun después de la Revolución de 1789. 
individualismo" modifica la acción de éste y hace peligrar su supervivencia: "Hemos tratado de aprehender la articulación entre el YO del individuo, el NOSOTROS de la agrupación y el ELLOS de la sociedad global" (Ion, 1997: 15).

A este método, Ilamado morfológico, Jacques lon añade una dimensión histórica. De esta manera, es Ilevado a recalcar la singularidad del caso francés en la historia reciente de las sociedades occidentales.

"El modelo militante, que se encuentra actualmente en crisis, está completamente relacionado con las características particulares del espacio público nacional" (Ion, 1997: 19). Al recordar que el "individualismo corresponde a la posibilidad de pensar la sociedad como una suma de individuos, cuya existencia autónoma se da previamente a su inserción en grupos de pertenencia y redes de dependencia" (Ion, 1997: 20), la asociación, en el sentido genérico del término, sería lo propio de las sociedades modernas (en oposición a las solidaridades tradicionales: gremio, familia, etc.). La sociedad francesa ha proscrito más que cualquier otra los cuerpos intermedios. En teoría, el ideal republicano excluye cualquier forma de agrupación que se interponga entre el ciudadano y la nación. Después de la proliferación de los clubes políticos durante la Revolución y hasta 1792, la vida asociativa habría sido casi nula (lo cual es evidentemente falso). En realidad, como muestra Maurice Agulhon (1988), los gobiernos de turno temen las asociaciones religiosas por un lado (las congregaciones) y las asociaciones de extrema izquierda por el otro.

Las leyes sobre el derecho sindical de 1884 y sobre el derecho de asociación de $1905^{25}$ responden al "temor" de que esas asociaciones reactiven el "comunitarismo" en vez de liberar al individuo y, de manera más prosaica, a las reticencias del campo político que sufre una competencia (tradición centralizadora, temor a lo religioso, a los obreros y revolucionarios). En ese contexto específico, se constituyen numerosas organizaciones que intervienen en el espacio público. No obstante, "al estudiarlas desde el punto de vista de sus modalidades de estructuración y de funcionamiento -lo que hemos Ilamado sus características formales-, pareciera que el conjunto de esas agrupaciones pudiera ser examinado, al menos hasta hace poco, como variantes de un mismo modelo, que llamamos de manera provisoria el modelo francés de asociación" (Agulhon, 1988: 47). Este modelo puede caracterizarse como una suerte de arbitraje entre los dos polos que permiten describir habitualmente cualquier organización social: el polo comunitario por un lado, y el polo societario o contractualista por el otro. El modelo francés asume ambos polos, pero "como si la dimensión comunitaria, negada en el plano jurídico, reapareciera en la organización y el funcionamiento cotidiano" (Agulhon, 1988: 54). La propensión al comunitarismo se mantuvo durante casi un siglo como una dimensión esencial de la vida sindical. Las características de este sistema refuerzan

25 N.d.T.: En Francia, la legalización de los sindicatos es el resultado de la Ley de 1884, la cual comporta sin embargo algunas restricciones pues el sindicalismo sigue siendo prohibido en el sector público. De la misma manera, la Ley de separación de las Iglesias y del Estado de 1905 instituye en Francia las asociaciones culturales, pero con ciertas limitaciones: un número mínimo de miembros, miembros únicamente individuales (las asociaciones no pueden afiliarse), etc. 
la identidad colectiva. Conciernen tanto su estructuración en federaciones asociativas relacionadas entre sí a través de amplias redes ideopolíticas; el tratamiento muy específico que se da a los individuos, considerados simultánea e inseparablemente como ciudadanos anónimos y a la vez completamente involucrados en una intensa vida comunitaria, como el hecho de que la masa de los adherentes individuales contribuya a fortalecer tanto a cada uno como al conjunto.

La figura del militante, de la cual el militante comunista es el parangón, se desarrolló en este modelo mixto. Su legitimidad proviene de su posición en la intersección de dos conjuntos: el conjunto comunitario y la sociedad misma; debe provenir del mismo medio social que las personas a las que representa; es también guía, porque participa en una red más amplia, esencialmente vertical, que permite al primer conjunto acceder a un destino de otro nivel. Si pierde el contacto, se burocratiza; si no está inserto en una red, lo devuelven a un destino común.

Este militante del pasado se encuentra actualmente "superado" por un nuevo tipo de militante. Las organizaciones burocráticas y jerarquizadas pasarían a ocupar un segundo plano, siendo reemplazadas por agrupaciones más informales y descentralizadas (en el mundo laboral las coordinadoras sustituirían así a las grandes confederaciones sindicales). Sobre todo, el compromiso individual se volvería menos intenso, como si los militantes tuvieran especial cuidado en no dejarse atrapar en la lógica agotadora del exceso de compromiso y cuidarían que se respete más su individualidad; un ejemplo de aquello sería la reducción del número y de la duración de las reuniones, o también el debilitamiento de la sociabilidad militante. El compromiso total y duradero de quienes se entregan a su causa sería remplazado por un compromiso puntual, dispuesto a pasar de una causa a otra, y respecto del cual los individuos "distanciados" se negarían, por lo demás, a sacrificar su vida privada e identidad personal.

Es lo que se conoce como la tesis del "militante distanciado". De la constatación de la evolución de las prácticas militantes, de las formas de organización y de acción, pasamos progresivamente a un punto de vista normativo que encierra a los militantes del pasado en el infierno del "totalitarismo militante" y realiza implícitamente un elogio de las nuevas militancias "distanciadas". El estudio de Jacques lon (1997) tuvo un éxito sorprendente, con tanta más razón cuanto que se adaptaba al espíritu individualista de la época, valoraba a las nuevas militancias y despreciaba a las antiguas, en particular a los activismos obreros.

Este estudio generó una controversia animada principalmente por la cientista política Annie Collovald (2002), quien, en un artículo titulado Pour une sociologie des carrières morales des dévouements militants, puso en evidencia los supuestos del estudio de Jacques lon.

La militancia no se explica por la militancia: ése fue el punto de vista adoptado por la autora. Para Annie Collovald (2002: 179), los estudios como el de Jacques lon se limitan a asumir los puntos de vista de los actores pasando por alto "las investigaciones sobre el trabajo histórico y colectivo de construcción de las 'causas'". 
Toda la temática de la militancia "distanciada" está construida en base a un sistema de oposiciones al pasado que presenta numerosas debilidades: por una parte, esta temática hace del militante del pasado un militante "total", sin restituir toda la complejidad del compromiso. Por otra, destaca un proceso de individuación "comodín", que no explica gran cosa, y precisa más bien ser explicado. Efectivamente, las relaciones en el mundo social cambiaron, incluso en el medio obrero, pero el proceso de individuación alude a un problema sin duda muy complejo ${ }^{26}$.

La reivindicación de ruptura de parte de los NMS con un pasado deliberadamente ennegrecido y simplificado remite a una "problemática de combate", que apunta a deslegitimar tanto el marxismo como el movimiento obrero pasando por alto la autonomía en la delegación (el sentido de sí mismo, la dignidad personal, el guardar distancias), incluso en la militancia comunista; reduciendo también el pasado a un elemento cuantitativo, como si los valores (la dignidad obrera, etc.) no estuvieran en el centro de las luchas pasadas. La "novedad" no sólo se constata; constituye también un recurso político en las luchas entre militantes establecidos y aspirantes a la militancia. En este caso, se justifica una dosis de anacronismo...

La omnipresencia de la retórica de la persona hace olvidar que nada es más ilusorio para un sociólogo como la "persona"; por ejemplo la oposición entre recursos individuales y colectivos no significa gran cosa, pues los recursos individuales son recursos colectivos personalmente apropiados: "los recursos individuales son esencialmente recursos colectivos reapropiados de manera personal. Son eludidos por los cuestionamientos acerca del conjunto de los recursos de los cuales disponen los actores en los diferentes espacios donde los han adquirido, acerca de lo que los estimula y los hace capaces de adoptar un modo personal de presentación, acerca de las oportunidades sociales y políticas a su alcance para interactuar con los demás, y finalmente acerca del valor de este modo de presentación en un contexto histórico y político preciso" (Collovald, 2002: 194). Con este elogio de la persona, la sociología de la biografía se encuentra borrada, olvidada y los indicadores usados pasan a ser demasiado groseros y poco confiables. Toda esta ideología oculta el modelo de compromiso e ideal de sí mismo característico de las fracciones de las clases medias intelectuales y en ascenso (pero también de otras fracciones de las clases medias).

Para Annie Collovald, sin negar las mutaciones de la militancia, tanto el compromiso de ayer como el de hoy deben mucho a las mismas metodologías: "las disposiciones hacia el compromiso no dependen directamente de las formas de pertenencia social. Son impulsadas por el encuentro entre las dinámicas de las trayectorias sociales y de las oportunidades, construidas socialmente y políticamente, ofrecidas a las aspiraciones, proyectos o ideales preconstituidos para realizarse" (Collovald, 2002: 194).

26 Se debe distinguir entre los procesos históricos de individuación y las filosofías sociales, las cuales quieren ver en la modernidad el advenimiento de un individuo más "libre". La ideología del individuo "libre" constituye así una de las dimensiones de los procesos de individuación. Para citar un solo ejemplo, la generalización de la enseñanza secundaria-superior expande también aquella ideología más conforme con los mitos escolares de la educación superior. Véase Bernard Pudal (2008). 


\section{V. ¿HACIA UNA CUARTA CONFIGURACIÓN?}

Esta controversia ha sido beneficiosa, en la medida en que parece llevar a una recomposición de los estudios franceses, en la cual las oposiciones entre generaciones de investigadores, herramientas de análisis y movimientos sociales estudiados, lejos de radicalizarse, dan más bien lugar a combinaciones, análisis comparados entre épocas de militancia, "alianzas" entre investigadores antiguos y "nuevos", para usar un lenguaje más político. En vez de oponer la sociología de las carreras al estilo americano (Howard Becker o Everett Hugues) y las trayectorias biográficas (Pierre Bourdieu), se busca asociar estas dos maneras de dar cuenta de lógicas sociales y personales de compromiso. También se recurre a esquemas de análisis provenientes de la sociología de los movimientos sociales estadounidenses, pero en el marco de estudios preocupados por la construcción social de las causas y la historia social de los grupos en movimiento. En efecto, en vez de oponer el método "individualista" y el método "sociológico", se trata de llevar a cabo una sociología de la dominación clásica, no obstante liberada de su legitimismo y de sus usos mecanicistas. Finalmente, más que debatir eternamente acerca del desinterés, se propone llevar a cabo análisis "procesuales" de la militancia ${ }^{27}$ y/o tratar de identificar dentro de la actividad militante fases en las que se alternan momentos "desinteresados" y momentos en que la percepción de las retribuciones, y hasta su búsqueda consciente, constituyen una de las dimensiones de la acción militante. El intento de comprender mejor la mezcla de lo reflexivo y de lo no-reflexivo, de la evaluación de los costos y de las retribuciones de la militancia de parte de los actores, se convierte en el objeto de análisis.

En esta nueva configuración, el cuestionario de los estudios sobre la militancia se extiende considerablemente. Para entender el compromiso militante, los investigadores se interesan cada vez más por los períodos o por las lógicas de desinvolucramiento. Un trabajo reciente bajo la dirección de Olivier Fillieule (2005) es íntegramente dedicado a ese tipo de pregunta, de la cual se espera que permita aclarar, al revés, las fases de compromiso intenso.

Más que hablar de militancia "distanciada", surge una pregunta fundamental: ¿cómo estudiar los efectos de procesos históricos de "individuación" (y no de individualismo) sobre las prácticas militantes? En esa perspectiva, tomar en cuenta las mutaciones de las disposiciones hacia la militancia en relación con las transformaciones de los sistemas de enseñanza, en particular la generalización de la enseñanza secundaria-superior a partir de los años sesenta, se transforma en una interrogante clave ${ }^{28}$.

Finalmente, a la militancia preferentemente estudiada hasta ahora (primero el activista obrero, el activista de los NMS, de los nuevos sindicalismos, de las nuevas causas y luego del altermundialismo) se añaden estudios acerca de las militancias olvidadas, con el objetivo de interrogar lateralmente las militancias de izquierda; las militancias del centro y de la

27 Véase el número de la Revue Française de Science Politique dirigido por Olivier Fillieule y Nonna Mayer (2001).

28 Véase Frédérique Matonti y Franck Poupeau (2004). 
derecha; las militancias católicas ${ }^{29}$; los compromisos populares y sus asociaciones, por ejemplo el compromiso voluntario en los cuerpos de bomberos de jóvenes que pertenecen a menudo a las clases populares (Retière, 1994). Además, los "compromisos" estudiados ya no se limitan a las movilizaciones colectivas o a las causas, sino que abarcan también los "compromisos profesionales" que pueden ser analizados como maneras militantes de trasladar hacia el universo del trabajo las propensiones a la militancia. Desde este punto de vista, el trabajo pionero de Francine Muel-Dreyfus (1984) sobre los educadores del período post-1968 abrió el camino a las investigaciones cuyo proyecto consistía en reintroducir el psicoanálisis o una mirada clínica en el estudio de los compromisos militantes, considerados simultáneamente como "libidinales" y "sociales".

En suma, poco a poco, lo que pasa a ocupar un lugar central es menos la oposición entre un estado anterior ("el militante total") y un nuevo estado ("el militante distanciado") como las filiaciones y las continuidades, aunque disruptivas, como lo atestigua la evolución del DBMOF, que se transforma en Dictionnaire Biographique du Mouvement Ouvrier-Mouvement Social para el período 1945-1968, dando cuenta al mismo tiempo de una filiación y de una diferencia ${ }^{30}$. Ocurre lo mismo con el creciente interés hacia la crisis de mayo-junio del 68, hacia sus causas y sus efectos sobre las biografías de militantes y/o de "hijos" de militantes, sobre las conversiones y renacimientos a la militancia, que se transforma en un tema central, como lo demuestra la gran obra colectiva acerca de Mayo-Junio del 68 publicada por la editorial de l'Atelier en enero de $2008^{31}$.

Finalmente, en esta última configuración -caracterizada por la ampliación del cuestionario científico, la multiplicidad de las vías comparatistas y la historia desde luego simbolizada por las investigaciones acerca de mayo-junio del 68 en un sentido amplio- asistimos más bien a una reconfiguración, en la que se acumulan los logros y hallazgos de las configuraciones anteriores. Subrayamos finalmente que existe cierta homología entre las dos primeras configuraciones y las dos últimas: más allá de sus diferencias, los investigadores tienen en común su propio deseo de compromiso y las oposiciones generacionales son también el reflejo de la evolución de las luchas sociales, del movimiento obrero en este espacio de movimientos sociales en vía de solidificación y de interacción con determinadas franjas del campo político y del campo intelectual (Mathieu, 2007).

29 Véase en este número el artículo de Julien Fretel (2011).

30 Tres volúmenes han sido publicados.

31 El libro reúne las investigaciones de una treintena de colaboradores, entre los cuales se encuentran numerosos especialistas en movimientos sociales, huelgas, protestas, etc. Véase Damamme et al. (2008). 


\section{BIBLIOGRAFÍA}

Actes du Colloque International de Beauvais, 6 y 7 de mayo de 1994, Archives Départementales de l'Oise.

Agrikoliansky, Eric (2002): La Ligue Française des Droits de L'Homme et du Citoyen depuis 1945, L'Harmattan, París.

Agulhon, Maurice (1988): Histoire vagabonde, tomos 1 y 2, Seuil, París.

Berlivet, Luc y Frédéric Sawicki (1994): "La foi dans I'engagement. Les militants syndicalistes CFTC de Bretagne dans l'après-guerre", Politix, 27, pp. 111-142.

Bourdet, Yvon (1976): Qu'est-ce qui fait courir les militants? Analyse sociologique des motivations et des comportements, Stock, París.

Bourdieu, Pierre (1984): "La délégation et le fétichisme en politique", Actes de la Recherche en Sciences Sociales, 52/53, pp. 49-55.

Bruneau, Ivan (2011): "La Confederación Campesina: Un sindicato agrícola líder del movimiento altermundialista francés. Análisis de una situación paradójica", Revista de Sociología, 25.

Chambelland, Colette (1999): Pierre Monatte, une autre voix syndicaliste, Éditions de l'Atelier, París.

Charle, Christophe (1996): “Du bon usage de la biographie comparée ou les trois âges de la biographie collective", en Michel Dreyfus, Nathalie Viet de Paule y Claude Pennetier (dir.): La part des militants, Éditions de l'Atelier, París, pp. 51-71.

Chazel, François (1986): "Individualisme, mobilisation et action collective", en Pierre Birnbaum y Jean Leca (dir.): Sur l'individualisme, Presses de Sciences Po, París, pp. 244-268.

Collovald, Annie (2002): "Pour une sociologie des carrières morales des dévouements militants", en Annie Collovald (dir.): L'humanitaire ou le management des dévouements. Enquête sur un militantisme de 'solidarité internationale' en faveur du Tiers-Monde, PUR, Rennes, pp. 177-229.

Crettiez, Xavier e Isabelle Sommier (2002): La France Rebelle, Michalon, París.

Damamme, Dominique, Boris Gobille, Frédérique Matonti y Bernard Pudal (dir.) (2008): Mai-Juin 68, Éditions de l'Atelier, París.

Dreyfus, Michel, Bruno Groppo, Claudio Ingerflom, Roland Lew, Claude Pennetier, Bernard Pudal y Serge Wolikow (eds.) (2004): Le Siècle des communismes, Seuil, París.

Fillieule, Olivier (1997): Stratégie de la rue. Les manifestations en France, Presses de Sciences Po, París. (dir.) (2005): Le désengagement militant, Belin, París.

Fillieule, Olivier y Nonna Mayer (dir.) (2001): “Devenirs militants", Revue Française de Science Politique, 51 (1-2), pp. 19-26.

Fretel, Julien (2011): "La sociología de los partidos políticos bajo el prisma de la derecha francesa", Revista de Sociología, 25.

Furet, François (1995) : Le passé d'une illusion, Robert Laffont-Calmann Lévy, París.

Gaxie, Daniel (1973): Les Professionnels de la politique, PUF, París.

(1977): "Economie des partis et rétributions du militantisme", Revue Française de Science Politique, 27 (1), pp. 123-154.

(2005): "Rétributions du militantisme et paradoxes de I'action collective", Revue Suisse de Science Politique, 11 (1), pp. 157-188. 
Hirschman, Albert O. (1970): Exit, Voice, and Loyalty: Responses to Decline in Firms, Organizations, and States, Harvard University Press, Cambridge, MA.

Ion, Jacques (1997): La fin des militants?, Éditions de l'Atelier, París.

Juhem, Philippe (2001): “Entreprendre en politique. De l'extrême gauche au PS: la professionnalisation politique des fondateurs de SOS-Racisme", Revue Française de Science Politique, 51 (1-2), pp. 131-153.

Kriegel, Annie (1964): Aux origines du communisme français, 1914-1920. Contribution à l'histoire du mouvement ouvrier français, La Haye, Mouton \& Co, París.

(1968): Les Communistes français: essai d'ethnographie politique, Seuil, París.

Lagroye, Jacques, Guy Lord, Lise Mounier-Chazel y Jacques Palard (1976): Les militants politiques dans trois fédérations départementales, Pedone, París.

Maitrion, Jean (dir.): Dictionnaire biographique du mouvement ouvrier français (DBMOF).

Mathieu, Lilian (2001): Mobilisations de prostituées, Belin, París.

(2004): Comment lutter?, Textuel, París.

(2007): “L'espace des mouvements sociaux", Politix, 20 (77), pp. 131-151.

Matonti, Frédérique y Franck Poupeau (2004): "Le Capital militant. Essai de définition", Actes de la Recherche en Sciences Sociales, 155, pp. 4-11.

Michels, Roberto (1971 [1911]): Les partis politiques: essai sur les tendances oligarchiques des démocraties, Flammarion, París.

Mothé, Daniel (1973): Le métier du militant, Seuil, París.

Muel-Drefus, Francine (1984): Le métier d'éducateur, Éditions de Minuit, París.

Neveu, Erik (1996): Sociologie des mouvements sociaux, La Découverte, París.

Noiriel, Gérard (1986): Les ouvriers dans la société française, Seuil, París.

Oberschall, Anthony (1973): Social conflict and social movements, Prentice-Hall, Englewood Cliffs, New Jersey.

Offerlé, Michel (1984): "Illégitimités et légitimation du personnel politique ouvrier en France avant 1914", Annales. Histoire, Sciences Sociales, 4, pp. 681-716.

Olson, Mancur (1978 [1966]): Logique de l'action collective, PUF, París.

Palmer Thompson, Edward (1963): The Making of the English Working Class, Vintage Books, Nueva York.

Perrot, Michelle (1996): "Le Dictionnaire comme lieu de mémoire", en Michel Dreyfus, Nathalie Viet de Paule y Claude Pennetier (dir.): La part des militants, Éditions de l'Atelier, pp. 13-33.

Prost, Antoine (1995): "L’histoire ouvrière en France aujourd'hui", Historiens et Géographes, 350, pp. 201-212.

Pudal, Bernard (1989): Prendre Parti. Pour une sociologie historique du PCF, Presses de Science Po, París. (2008): "Ordre symbolique et ordre scolaire", en Dominique Damamme, Boris Gobille, Frédérique Matonti y Bernard Pudal (dir.): Mai-Juin 68, Éditions de l'Atelier, París, pp. 62-74.

Quadruppani, Serge (1979): Des permanents des partis politiques, Métailié, París.

Retière, Jean-Noël (1994): "Être sapeur-pompier volontaire: du dévouement à la compétence", Genèses, 16 (16), pp. 94-113. 
Revel, Jacques (1996): Jeux d'échelles. La micro-analyse à l'expérience, Hautes Études/Gallimard/ Seuil, París.

Siméant, Johanna (1998): La Cause des sans-papiers, Presses de Science-Po, París.

Sommier, Isabelle (1998, reeditado en 2008): La violence politique et son deuil. L'après 68 en France et en Italie, PUR, Rennes.

(2003): Le renouveau des mouvements contestataires à l'heure de la mondialisation, Flammarion, París.

Tilly, Charles (1984): "Les origines du répertoire de l'action collective contemporaine en France et en Grande-Bretagne", Vingtième Siècle, 4, pp. 89-108. 